\title{
The Clinical Impact of GLP-1 Receptor Agonists in Type 2 Diabetes: Focus on the Long-Acting Analogs
}

\author{
Helena W. Rodbard, MD
}

\begin{abstract}
GLP-1 receptor agonists (GLP-1 RAs), introduced for clinical use in 2005, have excellent potency in reducing $\mathrm{HbA}_{1 \mathrm{c}}$ and mean glucose, improving fasting plasma glucose, inducing weight loss or protecting against the weight gain associated with insulin therapy, reducing appetite, and delaying gastric emptying. Two of these medications, liraglutide and semaglutide, appear to have cardioprotective effects as reflected in cardiovascular outcomes studies. The GLP-1 RAs are associated with gastrointestinal side effects that tend to diminish over time. They have very low risk of hypoglycemia unless used in conjunction with insulin or insulin secretagogues. Two coformulations of GLP-1 RAs together with long-acting basal insulin are available for daily use. The original GLP-1 RA, exenatide, requires twice-daily injections; two short-acting analogs are given once daily. Three currently available long-acting GLP-1 RAs are injected once weekly, providing greater convenience and potentially improving patient adherence. Semaglutide appears to be the most effective in terms of $\mathrm{HbA}_{1 \mathrm{c}}$ reduction and weight loss. GLP-1 RAs can be combined with all classes of antihyperglycemic agents except DPP-4 inhibitors. Current studies are exploring the use of an implantable osmotic pump for long-term administration of a rapid acting analog (exenatide), an oral preparation of semaglutide, benefits for management of obesity and nonalcoholic steatohepatitis, and mechanisms of cardioprotective effects.
\end{abstract}

Keywords: Type 2 diabetes, GLP-1 receptor agonists, Clinical trials, Cardiovascular outcome trials, Pharmacotherapy.

\section{Introduction}

$\mathbf{G}$ LP-1 ReCEPTOR AgONISTs (GLP-1 RAs) are an important, well-established therapeutic option for management of patients with type 2 diabetes, ${ }^{1,2}$ and may be used alone, with oral antihyperglycemic agents, with insulin, or as coformulations with long-acting insulins. These agents are highly effective in terms of reduction of $\mathrm{HbA}_{1 \mathrm{c}}$, weight reduction (or to minimize weight gain when coadministered with insulin or sulfonylureas), appetite suppression, reduced glycemic variability, and have low risk of hypoglycemia. GLP-1 RAs can be classified as rapid or long acting and in terms of homology to GLP-1 or to exendin-4. Table 1 summarizes their pharmacokinetic properties.

Of particular interest when treating people with diabetes is cardiovascular safety. The risk of death from any cause in people with diabetes is up to twice that of the general population $^{3}$ and the risk of death from cardiovascular causes is up to fourfold that of people without diabetes. ${ }^{4}$ Liraglutide and semaglutide have beneficial effects in cardiovascular outcome trials.

\section{Exenatide}

Exenatide was the first GLP-1 RA approved for clinical use in the United States in 2005. The original formulation of exenatide is a short-acting medication and requires injections twice per day (Table 1). Subsequently, liraglutide was introduced; it has longer duration of action so that it can be used once daily (Table 1). Another short acting GLP-1 RA, lixisenatide, was approved for once-daily therapy (Table 1). Three longer lasting preparations that can be given once weekly are currently available in the United States: exenatide extended release (ER), dulaglutide, and semaglutide (Table 1). Another long-acting preparation, albiglutide, was withdrawn from the market in the United States, possibly 
Table 1. GLP-1 Receptor Agonists: Pharmacokinetic Profiles

\begin{tabular}{lll}
\hline Agent & Half-life $\left(T_{1 / 2}\right)$ & \multicolumn{1}{c}{$T_{\max }$} \\
\hline Short Acting & & \\
$\quad$ Exenatide bid & $2.4 \mathrm{~h}$ & $2 \mathrm{~h}$ \\
$\quad$ Lixisenatide $q d$ & $3 \mathrm{~h}$ & $1-3.5 \mathrm{~h}$ \\
$\quad$ Liraglutide $q d$ & $13 \mathrm{~h}$ & $8-12 \mathrm{~h}$ \\
Long Acting & & \\
Dulaglutide $q w$ & $\sim 4$ days & $24-48 \mathrm{~h}$ \\
Exenatide $q w$ & $7-14$ days & $6-7$ weeks \\
Semaglutide $q w$ & $\sim 7$ days & $1-3$ days \\
\hline
\end{tabular}

due to limited efficacy. A once-daily oral preparation of semaglutide is currently undergoing clinical trials ${ }^{5}$ in a development program known as PIONEER. An alternative approach, now being explored in clinical trials, is to administer a short-acting agonist, exenatide, using an implantable osmotic pump. ${ }^{6}$

The structure of exenatide is based on exendin-4, a peptide from Gila monster saliva with limited homology with human GLP-1. Accordingly, it may have a higher incidence of allergic reactions and neutralizing antibodies than medications with a higher degree of homology with GLP-1. Subsequently, several GLP-1 RA analogs were developed with increased potency and increased duration of action. ${ }^{7}$ Tables 2-4 summarize the effectiveness of exenatide ER and the other GLP-1
RAs used for management of people with diabetes. There is a small increased risk of mildly elevated pancreatic lipase and amylase and a small increased risk of pancreatitis that is weakly associated with all of the GLP-1 RA preparations. However, there is no credible evidence of increased risk of pancreatic or other malignancies in people receiving either short- or long-acting GLP-1 RAs.

Exenatide can be continuously infused using a small implantable osmotic minipump that continuously delivers exenatide for 3-6 months. 8,9 In a randomized, open-label, phase 2 study, patients with poorly controlled type 2 diabetes receiving metformin were treated using ITCA 650 delivering $20 \mu \mathrm{g}$ of exenatide/day for 12 weeks followed by $60 \mu \mathrm{g} /$ day for 12 weeks. These patients experienced significant reductions in $\mathrm{HbA}_{1 \mathrm{c}}$ of $-1.4 \%$ and reductions in body weight of $-3.1 \mathrm{~kg}$ during the initial 24-week treatment period, and these effects were maintained during a 24 -week extension. ${ }^{10}$ In another recent study, 60 patients with longstanding, uncontrolled type 2 diabetes $\left(\mathrm{HbA}_{1 \mathrm{c}} 10 \%-12 \%\right)$ were enrolled in a 39-week, open-label, phase 3 trial. The initial exenatide dose was $20 \mu \mathrm{g} /$ day for 13 weeks, then $60 \mu \mathrm{g} /$ day for 26 weeks. At the end of the trial there was a mean reduction of $\mathrm{HbA}_{1 \mathrm{c}}$ of $-2.8 \%$ and body weight was reduced by $-1.2 \mathrm{~kg}$, and $25 \%$ of patients achieved $\mathrm{HbA}_{1 \mathrm{c}}<7 \%$. The most common side effects, typical of the entire GLP-1 RA class, were nausea, vomiting, and diarrhea. Discontinuation of treatment related to side effects was low $(7 \%)$.

Table 2. Effectiveness Of Long-Acting Glp-1 Receptor Agonists: Exenatide Extended Release

\begin{tabular}{|c|c|c|c|c|}
\hline Study & Duration & Comparators & $\begin{array}{c}\text { HbAlc } \\
\text { Change (\%) }\end{array}$ & $\begin{array}{c}\text { Weight } \\
\text { Change (kg) }\end{array}$ \\
\hline DURATION-1 ${ }^{\mathrm{a}}$ & 30 weeks $(\mathrm{N}=295)$ & Exenatide ER & $-1.9 \%$ & -4.0 \\
\hline $\begin{array}{l}\text { Background meds.: } \\
1 \text { or } 2 \text { of the following: Metformin, } \\
\text { Sulfonylurea, or Thiazolidinedione }\end{array}$ & $\begin{array}{l}30 \text { weeks }(\mathrm{N}=295) \\
\text { 6-year extension } \\
(\mathrm{N}=136)\end{array}$ & $\begin{array}{l}\text { Exenatide bid } \\
\text { Exenatide ER }\end{array}$ & $\begin{array}{l}-1.5 \% \\
-1.6 \%\end{array}$ & -4.2 \\
\hline DURATION- $2^{\mathrm{b}}$ & 26 weeks & Exenatide ER & $-1.6 \%$ & -2.7 \\
\hline $\begin{array}{l}\text { Background meds.: } \\
\text { Metformin } \\
\mathrm{N}=491\end{array}$ & & $\begin{array}{l}\text { Sitagliptin } \\
\text { Pioglitazone }\end{array}$ & $\begin{array}{l}-1.0 \% \\
-1.4 \%\end{array}$ & $\begin{array}{l}-1.0 \\
+3.3\end{array}$ \\
\hline DURATION-3 & 3-year extension & Exenatide ER Insulin glargine & $-1.0 \%$ & -2.6 \\
\hline $\begin{array}{l}\text { Background meds.: } \\
\quad \text { Metformin } \pm \text { sulfonylurea } \\
\mathrm{N}=456\end{array}$ & & & $-0.8 \%$ & +1.4 \\
\hline DURATION-4 ${ }^{\mathrm{b}}$ & 26 weeks & Exenatide ER & $-1.5 \%$ & -2.0 \\
\hline $\begin{array}{l}\text { Background meds.: } \\
\text { Drug Naïve } \\
\mathrm{N}=820\end{array}$ & & $\begin{array}{l}\text { Metformin } \\
\text { Pioglitazone } \\
\text { Sitagliptin }\end{array}$ & $\begin{array}{l}-1.5 \% \\
-1.6 \% \\
-1.2 \%\end{array}$ & $\begin{array}{l}-2.0 \\
+1.5 \\
-0.8\end{array}$ \\
\hline DURATION-5 & 24 weeks & Exenatide ER & $-1.6 \%$ & -2.3 \\
\hline $\begin{array}{l}\text { Background meds.: } \\
\text { Drug naïve, or oral agents } \\
\mathrm{N}=252\end{array}$ & & Exenatide bid & $-0.9 \%$ & -1.4 \\
\hline DURATION-6 & 26 weeks & Exenatide ER & $-1.3 \%$ & -2.7 \\
\hline $\begin{array}{l}\text { Background meds.: } \\
\text { Metformin } \\
\mathrm{N}=911\end{array}$ & & $\begin{array}{l}\text { Liraglutide } \\
1.8 \mathrm{mg} / \text { day }\end{array}$ & $-1.5 \%$ & -3.6 \\
\hline
\end{tabular}

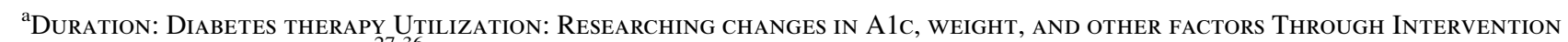
WITH EXENATIDE ONCE WEEKLY ${ }^{27-36}$

${ }^{b}$ DuRATION-2 and Duration-4 were double blind; other studies were open label. 
Table 3. Effectiveness of Long-Acting GLP-1 Receptor Agonists: Dulaglutide ${ }^{37-44}$

\begin{tabular}{|c|c|c|c|c|}
\hline Study & Treatment arms & $\begin{array}{l}\text { Study duration } \\
\text { (weeks) }\end{array}$ & $\begin{array}{c}A_{1 c} \text { change } \\
(\%)\end{array}$ & $\begin{array}{c}\text { Weight } \\
\text { change }(k g)\end{array}$ \\
\hline \multirow{2}{*}{$\begin{array}{l}\text { AWARD-1: background } \\
\text { metformin and pioglitazone }\end{array}$} & Dulaglutide $1.5 \mathrm{mg} \mathrm{qw}$ & \multirow[t]{2}{*}{52} & -1.51 & -1.3 \\
\hline & Exenatide twice daily $(10-\mu \mathrm{g})$ & & 0.99 & -1.3 \\
\hline \multirow[t]{3}{*}{ AWARD-2: metformin } & Dulaglutide $0.75 \mathrm{mg}$ qw & \multirow[t]{3}{*}{78} & -0.59 & -1.33 \\
\hline & Dulaglutide $1.5 \mathrm{mg} \mathrm{qw}$ & & -0.90 & -1.87 \\
\hline & Insulin glargine $\mathrm{qd}$ & & -0.62 & +1.28 \\
\hline \multirow{2}{*}{$\begin{array}{l}\text { AWARD-6: background } \\
\text { liraglutide } 26 \text { weeks }\end{array}$} & Dulaglutide $1.5-\mathrm{mg} \mathrm{qw}$ & \multirow[t]{2}{*}{26} & -1.42 & -2.9 \\
\hline & Liraglutide $1.8-\mathrm{mg}$ qd & & -1.36 & -3.6 \\
\hline \multirow[t]{3}{*}{ AWARD 10: 24 weeks } & Dulaglutide $0.75 \mathrm{mg} \mathrm{qw}+$ empagliflozin & \multirow[t]{3}{*}{24} & -1.21 & -2.6 \\
\hline & Dulaglutide $1.5 \mathrm{mg} \mathrm{qw}+$ empagliflozin & & -1.34 & -3.1 \\
\hline & Placebo qw + empagliflozin & & -0.54 & -2.1 \\
\hline
\end{tabular}

\section{Liraglutide}

Liraglutide was the second GLP-1 RA to become available in the United States. Its major advantage was longer half-life and hence greater effectiveness when administered as a once-daily injection. It was generally more effective than exenatide and has much higher homology (97\%) with human GLP-1, and therefore, a lower risk of immunogenicity and allergic reactions.

Liraglutide was evaluated in a phase 3 clinical program known as LEAD (Liraglutide Effect and Action in Diabetes), using monotherapy and combination therapy, with multiple comparators. ${ }^{11-16}$ Liraglutide administered once daily demonstrated significant $\mathrm{HbA}_{1 \mathrm{c}}$ reductions ranging from $-0.8 \%$ to $-1.1 \%$ with the lower dose $(1.2 \mathrm{mg} / \mathrm{day})$, and from $-1.0 \%$ to $-1.5 \%$ with the higher dose $(1.8 \mathrm{mg} /$ day $)$. Significant weight reductions were demonstrated with weight loss in these studies ranging from -2.2 to $-5.9 \mathrm{lbs}$ with the lower dose $(1.2 \mathrm{mg} /$ day $)$ and from -4.0 to $-7.3 \mathrm{lbs}$ with the higher dose $(1.8 \mathrm{mg} /$ day $)$.

\section{Insulin Degludec/Liraglutide Coformulation}

Because of the attractiveness of simultaneous initiation of therapy with a GLP-1 RA and a long-acting basal insulin, a coformulation of liraglutide and insulin degludec was developed and found to be both effective and well tolerated. It is administered as one injection per day, thereby providing convenience and hopefully resulting in better compliance. Its use markedly reduces the weight gain associated with insulin therapy and the gastrointestinal side effects of a GLP-1 RA. For patients who require more than $50 \mathrm{U}$ of insulin per day, one can use the separate preparations of the two medications so that they can be titrated independently.

In a development program known as DUAL, the efficacy and safety of the coformulation of insulin degludec and liraglutide were evaluated. ${ }^{17-22}$ In a 52-week comparison of IDegLira with insulin degludec or liraglutide alone, ${ }^{22}$ the mean $\mathrm{HbA}_{1 \mathrm{c}}$ at 52 weeks was reduced by $1.84 \%$ in the IDegLira group, $1.40 \%$ in the insulin degludec group, and $1.21 \%$ in the liraglutide group. Seventy-eight percent of the patients on IDegLira achieved an $\mathrm{HbA}_{1 \mathrm{c}}$ of $<7 \%$ compared with $63 \%$ of patients receiving insulin degludec and $57 \%$ of those receiving liraglutide. The mean fasting plasma glucose at the end of the trial was similar for patients receiving IDegLira or insulin degludec but higher in the liraglutide group. At 52 weeks, the daily insulin dose was $37 \%$ lower with IDegLira than with insulin degludec. IDegLira was associated with a greater decrease in body weight of $2.8 \mathrm{~kg}$, and a $37 \%$ lower rate of hypoglycemia compared with insulin degludec. 22

\section{Lixisenatide}

Lixisenatide is another GLP-1 RA available for once-daily use. Its half-life is shorter than that of liraglutide (Table 1).

Table 4. Effectiveness of Long-Acting GLP-1 Receptor Agonists: Semaglutide ${ }^{45-53}$

\begin{tabular}{|c|c|c|c|c|}
\hline Study & Dose $(m g)$ & $\begin{array}{l}\text { Study duration } \\
\text { (weeks) }\end{array}$ & $\begin{array}{l}H b A_{1 c}(\%) \\
\text { change }\end{array}$ & $\begin{array}{l}\text { Weight } \\
\text { change (pounds) }\end{array}$ \\
\hline \multirow[t]{3}{*}{ SUSTAIN-1: semaglutide (monotherapy) } & 0.5 & \multirow[t]{3}{*}{30} & -1.4 & -8.4 \\
\hline & 1.0 & & -1.6 & -10.4 \\
\hline & Placebo & & -0.1 & -2.6 \\
\hline \multirow[t]{3}{*}{ SUSTAIN-2: semaglutide (vs. sitagliptin) } & 0.5 & \multirow[t]{3}{*}{56} & -1.3 & -9.3 \\
\hline & 1.0 & & -1.5 & -12.1 \\
\hline & Sitagliptin $100 \mathrm{mg}$ & & -0.7 & -3.7 \\
\hline \multirow{2}{*}{ SUSTAIN-3 (vs. exenatide ER qw) } & 1.0 & \multirow[t]{2}{*}{56} & -1.4 & 10.6 \\
\hline & Exenatide ER $2 \mathrm{mg} \mathrm{qw}$ & & -0.9 & -4.4 \\
\hline \multirow{3}{*}{$\begin{array}{l}\text { SUSTAIN-4: semaglutide+insulin } \\
\quad \text { (vs. glargine U100) }\end{array}$} & 0.5 & \multirow[t]{3}{*}{30} & -1.2 & -7.1 \\
\hline & 1.0 & & -1.5 & -10.4 \\
\hline & Insulin glargine U100 & & -0.9 & +2.0 \\
\hline \multirow{3}{*}{$\begin{array}{l}\text { SUSTAIN-5: semaglutide added to } \\
\text { basal insulin (vs. placebo) }\end{array}$} & 0.5 & \multirow[t]{3}{*}{30} & -1.3 & -7.7 \\
\hline & 1.0 & & -1.7 & -13.2 \\
\hline & Placebo & & -0.2 & -2.6 \\
\hline
\end{tabular}

SUSTAIN, Semaglutide Unabated Sustainability in Treatment of type 2 diabetes. 
Lixisenatide is less effective than liraglutide in reducing $\mathrm{HbA}_{1 \mathrm{c}}$, fasting plasma glucose, and body weight, after 24 weeks of therapy, ${ }^{23}$ but it has greater efficacy in reducing the postprandial glucose levels both at 28 days and 24 weeks of therapy. ${ }^{23-25} \mathrm{HbA}_{1 \mathrm{c}}$ was reduced by $0.5 \%$ with morning injection and $0.4 \%$ with evening injection (placebo corrected). The 2-h postprandial glucose was reduced by $4.5 \mathrm{mmol} / \mathrm{L}$ (placebo corrected), and body weight was reduced by $0.9 \mathrm{~kg}$ (morning) or $0.6 \mathrm{~kg}$ (evening injection, placebo corrected). ${ }^{23}$ When lixisenatide was administered to people inadequately controlled with basal insulin alone, there was an average reduction in $\mathrm{HbA}_{1 \mathrm{c}}$ of $0.4 \%$, the percentage of subjects achieving an $\mathrm{HbA}_{1 \mathrm{c}}<7 \%$ increased from $12 \%$ for placebo to $28 \%$, the postprandial glucose was reduced by $3.8 \mathrm{mmol} / \mathrm{L}$, average body weight decreased by $1.3 \mathrm{~kg}$, and total insulin dose per day decreased by an average of $3.7 \mathrm{U} /$ day from a baseline of $55 \mathrm{U} /$ day. $^{25}$

\section{Lixisenatide/Insulin Glargine Coformulation}

Lixisenatide was introduced as a coformulation with insulin glargine, for the same reasons as for liraglutide combined with insulin degludec: convenience (one injection per day), reducing the extent of weight gain associated with insulin therapy, and a reduced risk of gastrointestinal side effects, as the doses of GLP-1 RA and insulin glargine are gradually escalated. This can be an effective manner to intensify therapy after failing to achieve goal with a mono- or combination oral therapy.

The LixiLan-L study evaluated 736 patients inadequately controlled on basal insulin alone or in combination with 1 or 2 oral agents. ${ }^{26}$ Patients treated with iGlarLixi showed reductions in $\mathrm{HbA}_{1 \mathrm{c}}$ of $-1.1 \%$ and with iGlar of $-0.6 \%$. A higher percentage of patients achieved the $\mathrm{HbA}_{1 \mathrm{c}}$ target level of $<7 \%$ $(P<0.0001): 55 \%$ of iGlarLixi patients reached $\mathrm{HbA}_{1 \mathrm{c}}<7 \%$ compared with $30 \%$ of iGlar patients. iGlarLixi also demonstrated significant reductions in 2 -h postprandial glucose (PPG) following a standardized liquid breakfast meal compared with iGlar. Mean body weight decreased by $0.7 \mathrm{~kg}$ with iGlarLixi and increased by $0.7 \mathrm{~kg}$ with iGlar $(P<0.0001)$. These improvements were accompanied by no increased risk of hypoglycemia.

\section{Long-Acting GLP-1 RAs for Weekly Administration}

Short-acting GLP-1 RAs require either twice-daily or daily administration. Currently, three long-acting agents are available, permitting administration on a weekly basis: exenatide ER, dulaglutide, and semaglutide. These offer greater convenience and therefore are expected to improve adherence.

There appears to be increased potency both in terms of $\mathrm{HbA}_{1 \mathrm{c}}$ reduction and weight loss in the longer acting preparations, semaglutide, dulaglutide, and exenatide ER, compared with the short-acting preparations.

\section{Exenatide ER}

Exenatide ER was the first weekly agent to become available. It consists of the same exenatide molecule that is absorbed slowly because it is encapsulated into a polymeric matrix of microspheres. This preparation is associated with a greater incidence of local reactions at the injection site that resolve spontaneously with time. The gastrointestinal side effects are less frequent and mild than for the other GLP-1 RAs, presumably because the final therapeutic blood level is achieved relatively slowly due to the gradual accumulation of the peptide over a period of up to 6-7 weeks. The phase 3 clinical trials of exenatide ER, consisting of six studies, were designated as the DURATION studies, ${ }^{27-36}$ (Table 2). These included two randomized placebo-controlled trials $\mathrm{s}^{27,31}$ and four open-label studies. The studies used several comparators and several different types of background medications and included subjects with $\mathrm{HbA}_{1 \mathrm{c}}$ ranging from $6 \%$ to $12 \%$. Most studies were 24-30 weeks in duration, but DURATION-1 was extended (open label) to 6 years and DURATION-3 was extended to 3 years. In all six studies, $\mathrm{HbA}_{1 \mathrm{c}}$ levels were reduced by $1.3 \%-1.6 \%$. The extent of $\mathrm{HbA}_{1 \mathrm{c}}$ reduction was linearly related to the baseline $\mathrm{HbA}_{1 \mathrm{c}}$ level, which is characteristic of nearly all medications for type 2 diabetes. Benefits in terms of $\mathrm{HbA}_{1 \mathrm{c}}$ and weight loss persisted through 6 years of follow-up in the open-label study although the number of subjects showed major attrition. The major side effects were gastrointestinal, as is characteristic for this entire class of therapeutic agents, both short and long acting. Minor reactions at the injection site were common for this agent, in contrast to all of the other GLP-1 RAs, presumably due to the polymeric microspheres. In the DURATION development program, exenatide ER was found to be superior in terms of its ability to lower $\mathrm{HbA}_{1 \mathrm{c}}$ to all agents studied, metformin, pioglitazone, sitagliptin, exenatide bid, and insulin glargine, with the exception of liraglutide. In DURATION-6, liraglutide $1.8 \mathrm{mg} /$ day was found to be more efficacious that exenatide ER. ${ }^{36}$

\section{Dulaglutide}

Dulaglutide is a long-acting GLP-1 analog suitable for onceweekly use. Dulaglutide shows considerably greater potency than the short-acting analogs discussed above and greater potency than exenatide ER. It has been evaluated in a series of 10 phase 3 clinical trials. The Assessment of Weekly AdministRation or AWARD clinical trials included ten phase 3 trials with multiple comparators. ${ }^{37-44}$ (Tables 2-4) The comparators included placebo, a sulfonylurea, exenatide, insulin glargine, and liraglutide in a variety of settings and patient populations.

When dulaglutide was added to prior therapy with the $\mathrm{SGLT}_{2}$ inhibitor empagliflozin, it resulted in additional improvement in $\mathrm{HbA}_{1 \mathrm{c}}$ and greater weight loss. ${ }^{44}$

The AWARD-1 trial compared dulaglutide $1.5 \mathrm{mg}$ versus exenatide $(10 \mu \mathrm{g})$ twice daily with background therapy of metformin and pioglitazone. Participants receiving dulaglutide ( $1.5 \mathrm{mg} /$ week) experienced dose-dependent reduction in $\mathrm{HbA}_{1 \mathrm{c}}$ level of $1.51 \%$, while those receiving exenatide showed a $0.99 \%$ reduction. Both groups experienced similar weight loss, $1.3 \mathrm{~kg}$, and similar incidence of gastrointestinal side effects. ${ }^{38}$ Thus, in subjects with metformin and pioglitazone background therapy, once-weekly dulaglutide therapy shows superior efficacy compared with exenatide, with similar tolerability.

The AWARD-2 trial ${ }^{39}$ compared dulaglutide (0.75 and $1.5 \mathrm{mg} /$ week) with insulin glargine titrated using a fasting blood glucose target of $100 \mathrm{mg} / \mathrm{dL}$, with both groups also receiving metformin treatment. The dulaglutide-treated participants exhibited an average $0.59 \%$ reduction in $\mathrm{HbA}_{1 \mathrm{c}}$ with the $0.75 \mathrm{mg}$ dose or a $0.9 \%$ reduction with the $1.5-\mathrm{mg}$ dulaglutide 
dose, compared with a $0.62 \%$ reduction in the group receiving insulin glargine. Dulaglutide demonstrated a dosedependent weight loss while the insulin glargine-treated group showed a $+1.28 \mathrm{~kg}$ weight gain. Thus, dulaglutide $(1.5 \mathrm{mg} /$ week) was superior to insulin glargine and a $0.75 \mathrm{mg}$ dose was noninferior.

The AWARD-6 trial ${ }^{43}$ compared dulaglutide $(1.5 \mathrm{mg}$ / week) versus liraglutide (1.8 mg daily), both with concomitant metformin, for 26 weeks. The dulaglutide and liraglutide groups showed nearly identical decreases in $\mathrm{HbA}_{1 \mathrm{c}}$ levels of $1.42 \%$ and $1.36 \%$, respectively. The liraglutide group demonstrated significantly greater weight loss $(3.6 \mathrm{~kg})$ compared with the dulaglutide group $(2.9 \mathrm{~kg})$. Adverse events were similar in the two groups.

Additional AWARD studies compared dulaglutide with several other comparators. ${ }^{40-44}$

\section{Semaglutide}

Semaglutide is a GLP-1 RA that has recently become available for treatment of type 2 diabetes using once-weekly injection at dosages of 0.5 or $1.0 \mathrm{mg} /$ week. The molecule has 94\% amino acid sequence homology to native GLP-1. Structural modifications render semaglutide more resistant to degradation by dipeptidyl peptidase-4, confer strong binding to albumin, and extend its half-life to $\sim 1$ week (Table 1 ). To minimize gastrointestinal side effects, therapy should be initiated at $0.25 \mathrm{mg} /$ week for 4 weeks and subsequently at $0.5 \mathrm{mg} /$ week.

Semaglutide is the latest addition to the once-weekly GLP-1 RA class of therapies. It has been extensively studied in the SUSTAIN clinical trials-Semaglutide Unabated Sustainability in Treatment of type 2 diabetes (Table 4$)^{45-51}$ and found to be more effective in terms of $\mathrm{HbA}_{1 \mathrm{c}}$ reduction and weight loss than placebo, sulfonylureas, exenatide, DPP-4 inhibitors, or basal insulin (glargine), either in the presence or absence of oral agents such as metformin. Semaglutide results in $\mathrm{HbA}_{1 \mathrm{c}}$ reduction and weight loss that are statistically and clinically significant. The combination of $\mathrm{HbA}_{1 \mathrm{c}}$ reduction and weight loss was seen in more than $75 \%$ of subjects in a series of five clinical trials (SUSTAIN-1 through SUSTAIN-5). ${ }^{45-51}$ There is a modest increase in potency of the higher $1.0 \mathrm{mg} /$ week dose compared with $0.5 \mathrm{mg} /$ week. Gastrointestinal side effects are comparable to those of the other GLP-1 RAs and tend to become milder after continued use.

The phase $3 \mathrm{a}$ development program for semaglutide included subjects across the entire spectrum of diabetes progression (Table 4). There were five trials in the SUSTAIN 3a program. SUSTAIN-1 enrolled drug-naive patients with shorter duration of diabetes; SUSTAIN-2 enrolled patients receiving metformin and/or thiazolidinediones and the comparator was sitagliptin; in SUSTAIN-3, subjects had been receiving one or two oral antidiabetic agents and the comparator was once-weekly exenatide ER; in SUSTAIN-4, patients were receiving metformin with or without sulfonylureas and insulin, and in SUSTAIN-5, the patients had longer duration of diabetes and were being treated with basal insulin in both the semaglutide treatment and the placebo groups.

\section{$H b A_{1 c}$ reduction}

Reduction in $\mathrm{HbA}_{1 \mathrm{c}}$ was dose dependent with modest improvement as dose was increased from 0.5 to $1.0 \mathrm{mg} /$ week.
The reduction in $\mathrm{HbA}_{1 \mathrm{c}}$ was nearly maximal by 16 weeks and highly statistically significant. The odds ratio for achieving an $\mathrm{HbA}_{1 \mathrm{c}}$ of $7.0 \%$ with semaglutide compared with placebo was $\sim 15$ for the $0.5 \mathrm{mg} /$ week dosage and $\sim 30$ for the $1.0 \mathrm{mg} /$ week dosage. Similar odds ratios were observed when using a target $\mathrm{HbA}_{1 \mathrm{c}}$ of $6.5 \%$. Weight loss was also dose dependent: $-3.7 \mathrm{~kg}$ at the $0.5 \mathrm{mg} /$ week dosage and $-5.4 \mathrm{~kg}$ at $1.0 \mathrm{mg} /$ week after 30 weeks. ${ }^{45}$

\section{Composite endpoint}

$\mathrm{HbA}_{1 \mathrm{c}}$ reduction and weight loss. In an analysis of subjects achieving any degree of $\mathrm{HbA}_{1 \mathrm{c}}$ reduction $\geq 1 \%$ and any degree of weight loss $\geq 5 \%$ using data from all five SUSTAIN 3a clinical trials, significantly more subjects receiving semaglutide achieved this dual composite endpoint than any of the comparators. The proportion of subjects achieving this endpoint was generally greater with semaglutide 1.0 versus $0.5 \mathrm{mg}$, suggesting a dose-dependent effect. Semaglutide was well tolerated with a safety profile similar to that of the other GLP-1 RAs. ${ }^{45}$ SUSTAIN-6 was a cardiovascular outcome trial. $^{52}$

SUSTAIN-7 was a phase $3 \mathrm{~b}$ clinical trial that compared the effectiveness of semaglutide ( 0.5 or $1.0 \mathrm{mg} /$ week dose levels) and dulaglutide $(0.75 \mathrm{mg}$ or $1.5 \mathrm{mg} /$ week $)$ when added to previous therapy with empagliflozin. The lower dose of semaglutide was more effective than the higher dose of dulaglutide in reducing $\mathrm{HbA}_{1 \mathrm{c}}$ and achieving weight loss. The higher dose of semaglutide $(1.0 \mathrm{mg} /$ week $)$ reduced mean $\mathrm{A}_{1 \mathrm{c}}$ by $1.8 \%$ and average weight by 6.5 pounds, in comparison with an average $1.4 \%$ reduction in $\mathrm{HbA}_{1 \mathrm{c}}$ and 3.0 pounds weight loss for the group receiving the higher dose of dulaglutide $1.5 \mathrm{mg} /$ week. ${ }^{53}$

\section{Potential Mechanisms for Cardiovascular Protection}

GLP-1 exerts direct and indirect actions on the cardiovascular system, including effects on cardiomyocytes, blood vessels, and adipocytes. ${ }^{54}$ The GLP-1 RAs have beneficial effects on blood pressure ${ }^{55}$ and reduce postprandial lipoprotein levels. ${ }^{56}$ GLP-1 RAs have cardioprotective actions in preclinical models of cardiovascular ischemia, and shortterm studies in humans have shown beneficial effects on cardiac function in people with ischemic heart disease. GLP-1 receptor activation in the hypothalamus reduces appetite and contributes to weight loss. ${ }^{57}$ Obesity is a significant risk factor for atherosclerotic cardiovascular disease and increased risk of heart failure. Therefore, weight loss associated with the use of GLP-1 RA may contribute to potential cardioprotective effects. Furthermore, weight loss is associated with increased plasma adiponectin levels, which have been shown to protect against acute myocardial infarctions and cardiac hypertrophy. ${ }^{58}$

\section{Cardiovascular Outcome Trials for GLP-1 RAs}

Large randomized placebo-controlled trials have been conducted in patients with type 2 diabetes with high cardiovascular risk to evaluate the cardiovascular safety of four GLP-1 RAs: liraglutide and lixisenatide for daily administration, and semaglutide and exenatide ER for weekly administration (Table 5). 


\section{ELIXA: The Evaluation of Lixisenatide in Accute Coronary Syndrome}

The ELIXA trial compared lixisenatide with placebo in 6068 patients with type 2 diabetes who had an acute coronary event within 180 days and had a mean $\mathrm{HbA}_{1 \mathrm{c}}$ of $7.7 \%$, followed up for a median of 2.1 years. The primary outcome was a 4-point major adverse cardiovascular event (MACE) that added hospitalization for unstable angina. The hazard ratio (HR) for the primary outcome was 1.02 (noninferior) with $P<0.001$ for noninferiority and $P=0.81$ for superiority. ${ }^{59}$

\section{LEADER: Liraglutide effect and action in diabetes: evaluation of cardiovascular outcome results}

This study compared liraglutide $1.8 \mathrm{mg}$ once daily with placebo in 9340 patients with type 2 diabetes and established cardiovascular disease $(81 \%)$ or cardiovascular risk factors and a mean $\mathrm{HbA}_{1 \mathrm{c}}$ of $8.7 \%$, followed up for a median of 3.8 years. The HR for the primary outcome was 0.87 with $P<0.001$ for noninferiority and $P=0.01$ for superiority. ${ }^{60}$

\section{SUSTAIN-6: Trial to Evaluate Cardiovascular and Other Long-Term Outcomes with Semaglutide in Subjects with type 2 Diabetes}

SUSTAIN-6 compared semaglutide $(0.5$ and $1.0 \mathrm{mg}$ once per week) with placebo in 3297 patients with type 2 diabetes and established cardiovascular disease $(83 \%)$ or cardiovascular risk factors and a mean $\mathrm{HbA}_{1 \mathrm{c}}$ of $8.7 \%$, followed up for a median of 2.1 years. The HR was 0.74 with $P<0.001$ for noninferiority and $P=0.02$ for superiority. ${ }^{52}$

\section{EXSCEL: Exenatide study of cardiovascular event lowering}

EXSCEL was the cardiovascular trial with once-weekly exenatide ER. This study compared exenatide extendedrelease ( $2 \mathrm{mg}$ once per week) with placebo in 14,752 patients with type 2 diabetes and established cardiovascular disease $(73 \%)$ or without previous cardiovascular events and a me- dian $\mathrm{HbA}_{1 \mathrm{c}}$ of $8.0 \%$ followed up for a median of 3.2 years. The HR was 0.91 with $P<0.001$ for noninferiority and $P=0.06$ for superiority. ${ }^{61}$

A meta-analysis of the four cardiovascular trials reported to date evaluating cardiovascular safety of the GLP-1 RA included ELIXA, LEADER, SUSTAIN-6, and EXSCEL. ${ }^{62}$ These trials demonstrated cardiovascular safety, with findings from two trials (LEADER and SUSTAIN-6) showing significant reductions in the primary endpoint, a 3-point MACE outcome, including cardiovascular mortality, nonfatal myocardial infarction, or nonfatal stroke. Only liraglutide was associated with significant reductions in all-cause mortality and cardiovascular mortality, and only semaglutide was associated with a significant reduction in nonfatal stroke. The authors concluded that drugs in the class of GLP-1 RA can reduce the 3-point MACE, cardiovascular mortality, and allcause mortality risk, although to varying degrees for individual drugs and without safety concerns. If one assumes that all of the GLP-1 RAs were to show a class effect for cardioprotection and average the results of the LEADER, ELIXA, SUSTAIN-6, and EXSCEL studies, then the HR would be $0.90 .^{62}$

\section{Discussion}

The following considerations apply to commercially available GLP-1 RA class of therapies (Tables 2-4).

Use of GLP-1 RAs alone or as part of combination therapy with oral agents or insulin greatly improves the ability to achieve an $\mathrm{HbA}_{1 \mathrm{c}}$ target of either $6.5 \%$ or $7.0 \%$. GLP-1 RAs are synergistic with metformin, SGLT $_{2}$ inhibitors, insulins, and have been used in conjunction with pioglitazone.

GLP-1 RAs have been shown to be safe, effective, and well tolerated. The gastrointestinal side effects - nausea, vomiting, and diarrhea-generally decline in frequency and severity within a matter of weeks. Slower titration of dose of the GLP-1 RA can reduce the risk of these side effects.

$\mathrm{HbA}_{1 \mathrm{c}}$ reduction and weight loss are largely accomplished within 15 weeks and can be expected to have reached maximal

Table 5. Cardiovascular Outcome Trials for Four GLP-1 Receptor Agonists ${ }^{52,59-62}$

\begin{tabular}{|c|c|c|c|}
\hline Trial & Patient population & $\begin{array}{l}\text { Median } \\
\text { follow-up }\end{array}$ & $H R$ \\
\hline Lixisenatide ELIXA $^{59}$ & $\begin{array}{l}\text { T2D with acute cardiovascular } \\
\text { event } \leq 180 \text { days; } N=6058\end{array}$ & 25 Months & $\begin{array}{l}\mathrm{HR}=1.02 . \text { No significant } \\
\text { difference versus placebo } \\
\text { for 4-point MACE (3-point } \\
\text { MACE; or unstable angina } \\
\text { requiring hospitalization), } \\
\text { nor all-cause mortality. }\end{array}$ \\
\hline Liraglutide LEADER $^{60}$ & $\begin{array}{l}\text { T2D, age } \geq 50 \text { years; CVD or } \\
\text { CKD; or age } \geq 60 \text { years with } \\
\text { one risk factor; } N=9340\end{array}$ & 3.8 Years & $\begin{array}{c}\mathrm{HR}=0.85 \text { for all-cause death. } \\
\mathrm{HR}=0.87 \text { for } 3 \text {-point MACE } \\
\mathrm{HR}=0.78 \text { for CVD death. }\end{array}$ \\
\hline Exenatide qw EXSCEL ${ }^{61}$ & $\begin{array}{l}\text { T2D, } 70 \% \text { with prior cardiovascular } \\
\text { event; } N=14752\end{array}$ & 3.2 Years & $\mathrm{HR}=0.91$ for 3 -point $\mathrm{MACE}$ \\
\hline Semaglutide qw SUSTAIN-6 ${ }^{52}$ & $\begin{array}{l}\text { T2D, age } \geq 50 \text { years with CVD, } \\
\text { HF, or CKD, or } \geq 60 \text { years with } \\
\text { one risk factor; } N=3297\end{array}$ & 2.1 Years & $\mathrm{HR}=0.74$ for 3 -point $\mathrm{MACE}$ \\
\hline
\end{tabular}

CKD, chronic kidney disease; CVD, cardiovascular disease; EXSCEL, Exenatide Study of Cardiovascular Event Lowering; HF, heart failure; HR, hazard ratio; LEADER, Liraglutide Effect and Action in Diabetes: Evaluation of Cardiovascular Outcome Results; MACE, major adverse cardiovascular event; SUSTAIN, Trial to Evaluate Cardiovascular and Other Long-Term Outcomes with Semaglutide in Subjects with type 2 Diabetes; T2D, type 2 diabetes. 
effectiveness by 30 weeks. The reduction in $\mathrm{HbA}_{1 \mathrm{c}}$ and weight loss is dose dependent.

In addition to the reduction of $\mathrm{HbA}_{1 \mathrm{c}}$ and weight loss, the GLP-1 RAs reduce glycemic variability measured by several standard metrics (\% coefficient of variation, standard deviation, mean amplitude of glycemic excursions) and accompanied by an increase in the percentage of time in the target range. ${ }^{63-66}$

If the $\mathrm{HbA}_{1 \mathrm{c}}$ is $<8 \%$, or if the patient is at high risk for hypoglycemia for any reason (e.g., hypoglycemia unawareness, or history of severe or frequent hypoglycemia), it is advisable to reduce the dosage of insulin and/or other antihyperglycemic agents by a moderate amount to reduce the risk of hypoglycemia when adding another highly effective agent.

GLP-1 RAs are highly effective and even better tolerated when coformulated with insulin (liraglutide with insulin degludec, lixisenatide with insulin glargine U-100)). This ensures that dosage is escalated slowly and gradually.

Cardiovascular protection has been observed for liraglutide in the LEADER study. A smaller effect with borderline statistical significance was observed for exenatide ER in the EXSCEL trial but not for lixisenatide in the ELIXA. A cardiovascular outcome trial for dulaglutide is ongoing. It is worth noting that the curves for both liraglutide and semaglutide in the cardiovascular outcome trials (CVOTs) separate from placebo after more than 1 year. This is in contrast to the results reported in the EMPA-REG CVOT for empagliflozin, in which separation of the curves occurs within 3 months of initiation of the medication. This suggests that the mechanisms of cardiovascular benefit are distinctive for these two classes of medications.

For people with type 2 diabetes experiencing unacceptable levels of hypoglycemia while receiving insulin therapy, it may be possible to reduce or even eliminate the use of insulin by addition of highly effective therapies such as GLP-1 RAs.

Ongoing research and development can be expected to clarify the effectiveness and safety of the implantable osmotic pump for administration of exenatide or other relatively rapidly cleared analogs, the potential clinical utility of an oral preparation of semaglutide, ${ }^{67}$ and the effectiveness of GLP-1 RAs for management of obesity ${ }^{57,68}$ and of nonalcoholic hepatosteatosis. ${ }^{69}$

\section{Conclusions}

GLP-1 RAs are one of the most effective and well-tolerated class of therapies for type 2 diabetes. These medications are usually more effective in terms of $\mathrm{HbA}_{1 \mathrm{c}}$ reduction and weight loss than metformin, sulfonylureas, and DPP-4 inhibitors. The GLP-1 RA class of medications has a low risk of hypoglycemia, but adjustments of the doses of other medications are advisable, especially if the initial baseline $\mathrm{HbA}_{1 \mathrm{c}}$ is $<8 \%$, or if the patient is receiving insulin or sulfonylureas.

The effects of GLP-1 RAs appear to be additive with basal insulin. Lixisenatide is available as a fixed dose-ratio coformulation with insulin glargine U-100 and liraglutide is available as a fixed dose-ratio coformulation with insulin degludec. These coformulations facilitate slow and systematic titration of dose, which has the benefit of reduced gastrointestinal side effects related to the GLP-1 RA, reduced risk of hypoglycemia related primarily to the insulin, and often permit use of smaller doses for both medications than when they are used alone. Liraglutide has been demonstrated to be cardioprotective with respect to the prespecified 3component MACE.

\section{Acknowledgments}

The author thanks her colleagues, coworkers, and patients involved in several clinical trials.

\section{Author Disclosure Statement}

The author has served as a principal investigator, as a consultant, speaker, and advisor to companies that manufacture GLP-1 RAs, including AstraZeneca, Novo Nordisk, Sanofi, Boehringer Ingelheim, and Eli Lilly.

\section{References}

1. Garber AJ, Abrahamson MJ, Barzilay JI, et al.: Consensus statement by the American Association of Clinical Endocrinologists and American College of Endocrinology on the comprehensive type 2 diabetes management algorithm2016 executive summary Endocr Pract 2016;22:84-113.

2. American Diabetes Association: 8. Pharmacologic approaches to glycemic treatment: standards of medical care in diabetes-2018. Diabetes Care 2018;41(Suppl 1):S73-S85.

3. Tancredi M, Rosengren A, Svensson AM, et al.: Excess mortality among persons with type 2 diabetes. N Engl J Med 2015;373:1720-1732.

4. Centers for Disease Control and Prevention: National diabetes statistics report. 2017. www.cdc.gov.

5. Davies M, Pieber TR, Hartoft-Nielsen M-L, et al.: Effect of oral semaglutide compared with placebo and subcutaneous semaglutide on glycemic control in patients with type 2 diabetes: a randomized clinical trial. JAMA 2017;318: 1460-1470.

6. Henry RR, Rosenstock J, Logan DK, et al.: Continuous subcutaneous delivery of exenatide by ITCA 650 leads to sustained glycemic control and weight loss for 48 weeks in metformin-treated subjects with type 2 diabetes. J Diabetes Complications 2014;28:393-398.

7. Nauck MA, Meier JJ: Incretin hormones: their role in health and disease. Diabetes Obes Metab 2018;20(Suppl 1):5-21.

8. Rosenstock J, Buse JB, Azeem R, et al.: Efficacy and safety of ITCA 650, a novel drug-device GLP-1 receptor agonist, in type 2 diabetes uncontrolled with oral antidiabetes drugs: the FREEDOM-1 Trial. Diabetes Care 2018;41: 333-340.

9. Rosenstock J, Buse JB, Azeem R, et al.: Efficacy and safety of ITCA 650, a novel drug-device GLP-1 receptor agonist, in type 2 diabetes uncontrolled with oral antidiabetes drugs: the FREEDOM-1 trial. Diabetes Care 2018;41: 333-340.

10. Henry RH, Rosenstock J, Denham DS, et al.: Clinical impact of ITCA 650, a novel drug-device GLP-1 receptor agonist, in uncontrolled type 2 diabetes and very high baseline HbA1c: the FREEDOM-1 HBL (high baseline) study. Diabetes Care 2018;41:613-619.

11. Marre M, Shaw J, Brandle M, et al.: Liraglutide, a oncedaily human GLP-1 analogue, added to a sulphonylurea over 26 weeks produces greater improvements in glycaemic and weight control compared with adding rosiglitazone or placebo in subjects with type 2 diabetes (LEAD- 1 SU). Diabetic Med 2009;26:268-278.

12. Nauck M, Frid A, Hermansen K, et al.: Efficacy and safety comparison of liraglutide, glimepiride, and placebo, all in 
combination with metformin, in type 2 diabetes: the LEAD (liraglutideeffect and action in diabetes)-2 study. Diabetes Care 2009;32:84-90.

13. Garber A, Henry RR, Ratner R, et al.: Liraglutide, a once-daily human glucagon-like peptide 1 analogue, provides sustained improvements in glycaemic control and weight for 2 years as monotherapy compared with glimepiride in patients with type 2 diabetes. Diabetes Obes Metab 2011;13:348-356.

14. Zinman B, Gerich J, Buse JB, et al.: Efficacy and safety of the human glucagon-like peptide-1 analog liraglutide in combination with metformin and thiazolidinedione in patients with type 2 diabetes (LEAD-4 Met TZD). Diabetes Care 2009;32:1224-1230.

15. Russell-Jones D, Vaag A, Schmitz O, et al.: Liraglutide vs insulin glargine and placebo in combination with metformin and sulfonylurea therapy in type 2 diabetes mellitus (LEAD-5 met SU): a randomised controlled trial. Diabetologia 2009;52:2046-2055.

16. Buse JB, Rosenstock J, Sesti G, et al.: Liraglutide once a day versus exenatide twice a day for type 2 diabetes: a 26week randomized, parallel-group, multinational, open-label trial (LEAD-6). Lancet 2009;374:39-47.

17. Gough SC, Bode B, Woo V, et al.: Efficacy and safety of a fixed-ratio combination of insulin degludec and liraglutide (IDegLira) compared with its components given alone: results of a phase 3, open-label, randomised, 26-week, treat-to-target trial in insulin-naive patients with type 2 diabetes. Lancet Diabetes Endocrinol 2014;2:885-893.

18. Rodbard HW, Bode BW, Harris SB, et al.: Safety and efficacy of insulin degludec/liraglutide (IDegLira) added to sulphonylurea alone or to sulphonylurea and metformin in insulin-naïve people with type 2 diabetes: the DUAL IV trial. Diabet Med 2017;34:189-196.

19. Rodbard HW, Buse JB, Woo V, et al.: Benefits of combination of insulin degludec and liraglutide are independent of baseline glycated haemoglobin level and duration of type 2 diabetes. Diabetes Obes Metab 2016;18:40-48.

20. Holst JJ, Buse JB, Rodbard HW, et al.: IDegLira improves both fasting and postprandial glucose control as demonstrated using continuous glucose monitoring and a standardized meal test. J Diabetes Sci Technol 2015;10:389-397.

21. Billings LK, Doshi A, Gouet D, et al.: Efficacy and safety of IDegLira versus basal-bolus insulin therapy in patients with type 2 diabetes uncontrolled on metformin and basal insulin; DUAL VII randomized clinical trial. Diabetes Care 2018; 41:1009-1016.

22. Gough SC, Bode BW, Woo VC, et al.: One-year efficacy and safety of a fixed combination of insulin degludecand liraglutide in patients with type 2 diabetes: results of a 26week extension to a 26-week main trial. Diabetes Obes Metab 2015;17:965-973.

23. Ahrén B, Leguizamo Dimas A, Miossec P, et al.: Efficacy and safety of lixisenatide once-daily morning or evening injections in type 2 diabetes inadequately controlled on metformin (GetGoal-M). Diabetes Care 2013;36:2543-2550.

24. Kapitza C, Forst T, Coester HV, et al.: Pharmacodynamic characteristics of lixisenatide once daily versus liraglutide once daily in patients with type 2 diabetes insufficiently controlled on metformin. Diabetes Obes Metab 2013;15:642-649.

25. Riddle MC, Aronson R, Home P, et al.: Adding once-daily lixisenatide for type 2 diabetes inadequately controlled by established basal insulin: a 24-week, randomized, placebocontrolled comparison (GetGoal-L). Diabetes Care 2013; 36:2489-2496.
26. Wysham C, Bonadonna RC, Aroda VR, et al.: Consistent findings in glycaemic control, body weight and hypoglycaemia with iGlarLixi (insulin glargine/lixisenatide titratable fixed-ratio combination) vs insulin glargine across baseline HbA1c, BMI and diabetes duration categories in the LixiLan-L trial. Diabetes Obes Metab 2017;19:1408-1415.

27. Henry RR, Klein EJ, Han J, Iqbal N: Efficacy and tolerability of exenatide once weekly over 6 years in patients with type 2 diabetes: an uncontrolled open-label extension of the DURATION-1 study. Diabetes Technol Ther 2016; 18:677-686.

28. Drucker DJ, Buse JB, Taylor K, et al.: Exenatide once weekly versus twice daily for the treatment of type 2 diabetes: a randomised, open-label, non-inferiority study. Lancet 2008;372:1240-1250.

29. Wysham C, Bergenstal R, Malloy J, et al.: DURATION-2: efficacy and safety of switching from maximum daily sitagliptin or pioglitazone to once-weekly exenatide. Diabet Med 2011;28:705-714.

30. Blonde L, Pencek R, MacConell L: Association among weight change, glycemic control, and markers of cardiovascular risk with exenatide once weekly: a pooled analysis of patients with type 2 diabetes. Cardiovasc Diabetol 2015;14:12.

31. Diamant M, Van Gaal L, Stranks S, et al.: Once weekly exenatide compared with insulin glargine titrated to target in patients with type 2 diabetes (DURATION-3): an openlabel randomised trial. Lancet 2010;375:2234-2243.

32. Diamant M, Van Gaal L, Guerci B, et al.: Exenatide once weekly versus insulin glargine for type 2 diabetes (DURATION-3): 3 year results of an open-label randomised trial. Lancet Diabetes Endocrinol 2014;2:464-473.

33. Russell-Jones D, Cuddihy RM, Hanefeld M, et al.: Efficacy and safety of exenatide once weekly versus metformin, pioglitazone, and sitagliptin used as monotherapy in drugnaive patients with type 2 diabetes (DURATION-4): a 26week double-blind study. Diabetes Care 2012;35:252-258.

34. Blevins T, Ruggles J, Hardy E: Onset of glycemic and weight outcomes in patients initiating exenatide once weekly: the relationship of exenatide exposure with efficacy over the first 24 weeks of treatment. Diabetes Ther 2016;7:361-368.

35. Blevins T, Pullman J, Malloy J, et al.: DURATION-5: exenatide once weekly resulted in greater improvements in glycemic control compared with exenatide twice daily in patients with type 2 diabetes. J Clin Endocrinol Metab 2011;96:1301-1310.

36. Buse JB, Nauck M, Forst T, et al.: Exenatide once weekly versus liraglutide once daily in patients with type 2 diabetes (DURATION-6): a randomised, open-label study. Lancet 2013;381:117-124.

37. Gurung T, Shyangdan DS, O'Hare JP, et al.: A novel, longacting glucagon-like peptide receptor agonist: dulaglutide. Diabetes Metab Syndr Obes 2015;8:363-386.

38. Wysham C, Blevins T, Arakaki, et al.: Efficacy and safety of dulaglutide added onto pioglitazone and metformin versus exenatide in type 2 diabetes in a randomized controlled trial (AWARD-1). Diabetes Care 2014;37:2159-2167.

39. Giorgino F, Benroubi M, Sun JH, et al.: Efficacy and safety of once weekly dulaglutide versus insulin glargine in combination with metformin and glimepiride in type 2 diabetes patients (AWARD-2). Diabetes 2014;63(Suppl 1):A87.

40. Umpierrez G, Povedano ST, Manghi FP, et al.: Efficacy and safety of dulaglutide monotherapy versus metformin in type 2 diabetes in a randomized controlled trial (AWARD3). Diabetes Care 2014;37:2168-2176. 
41. Jendle J, Rosenstock J, Blonde L, et al.: Better glycemic control and less weight gain with once weekly dulaglutide versus once daily insulin glargine, both combined with premeal insulin lispro in type 2 diabetes patients (AWARD-4). Diabetes 2014;63:A246-A247.

42. Nauck M, Weinstock RS, Umpierrez GE, et al.: Efficacy and safety of dulaglutide versus sitagliptin after 52 weeks in type 2 diabetes in a randomized controlled trial (AWARD-5). Diabetes Care 2014;37:2149-2158.

43. Dungan KM, Povedano ST, Frost T, et al.: Once weekly dulaglutide versus once daily liraglutide in metformin treated patients with type 2 diabetes (AWARD-6): a randomized, open-label, phase 3, non-inferiority trial. Lancet 2014;384:1349-1357.

44. Ludvik B, Frías JP, Tinahones FJ, et al.: Dulaglutide as add-on therapy to SGLT2 inhibitors in patients with inadequately controlled type 2 diabetes (AWARD-10): a 24week, randomised, double-blind, placebo-controlled trial. Lancet Diabetes Endocrinol 2018;6:370-381.

45. Rodbard H, Bellary S, Hramiak I, et al.: Responder analysis of subjects achieving $\mathrm{HbAlc}$ reduction $>1 \%$ and body weight loss $>5 \%$ across SUSTAIN 1-5 clinical trials. Diabetes 2017;7(Suppl):Abstract P-0525.

46. Sorli C, Harashima SI, Tsoukas GM, et al.: Efficacy and safety of once-weekly semaglutide monotherapy versus placebo in patients with type 2 diabetes (SUSTAIN 1): a double-blind, randomised, placebo-controlled, parallelgroup, multinational, multicentre phase $3 \mathrm{a}$ trial. Lancet Diabetes Endocrinol 2017;5:251-260.

47. Ahrén B, Masmiquel L, Kumar H, et al.: Efficacy and safety of once-weekly semaglutide versus once-daily sitagliptin as an add-on to metformin, thiazolidinediones, or both, in patients with type 2 diabetes (SUSTAIN 2): a 56week, double-blind, phase $3 \mathrm{a}$, randomised trial. Lancet Diabetes Endocrinol 2017;5:341-354.

48. Ahmann AJ, Capehorn M, Charpentier G, et al.: Efficacy and safety of once-weekly semaglutide versus exenatide er in subjects with type 2 diabetes (SUSTAIN 3): a 56-week, open-label, randomized clinical trial. Diabetes Care 2018; 41:258-266.

49. Aroda VR, Bain SC, Cariou B, et al.: Efficacy and safety of once-weekly semaglutide versus once-daily insulin glargine as add-on to metformin (with or without sulfonylureas) in insulinnaive patients with type 2 diabetes (SUSTAIN 4): a randomised, open-label, parallel-group, multicentre, multinational, phase 3a trial. Lancet Diabetes Endocrinol 2017;5:355-366.

50. Rodbard HW, Lingway I, Reed J, et al.: Efficacy and safety of semaglutide once-weekly vs. placebo as add-on to basal insulin alone or in combination with metformin in subjects with type 2 diabetes (SUSTAIN-5). Diabetologia 2016;59: S364-S365, Abstract A-766.

51. Rodbard, HW, Lingvay I, Reed J, et al.: Semaglutide added to basal insulin in type 2 diabetes (SUSTAIN 5): a randomised, controlled trial. J Clin Endocrinol Metab. 2018 Eprint ahead of print 23 April 2018 https:/doi.org/10.1210/ jc.2018-00070.

52. Marso SP, Bain SC, Consoli A, et al.: Semaglutide and cardiovascular outcomes in patients with type 2 diabetes. $\mathrm{N}$ Engl J Med 2016;375:1834-1844.

53. Pratley RE, Aroda VR, Lingvay I, et al.: Semaglutide versus dulaglutide once weekly in patients with type 2 diabetes (SUSTAIN 7): a randomised, open-label, phase $3 \mathrm{~b}$ trial. Lancet Diabetes Endocrinol 2018;6:275-286.

54. Ussher JR, Drucker DJ: Cardiovascular biology of the incretin system. Endocr Rev 2012;33:187-215.
55. Schwartz EA, Koska J, Mullin MP, et al.: Exenatide suppresses postprandial elevations in lipids and lipoproteins in individuals with impaired glucose tolerance and recent onset type 2 diabetes mellitus. Atherosclerosis 2010;212:217-222.

56. Meier JJ, Gethmann A, Gotze O, et al.: Glucagon-like peptide 1 abolishes the postprandial rise in triglyceride concentrations and lowers levels of non-esterified fatty acids in humans. Diabetologia 2006;49:452-458.

57. Flint A, Raben A, Astrup A, et al.: Glucagon-like peptide 1 promotes satiety and suppresses energy intake in humans. J Clin Invest 1998;101:515-520.

58. Shibata R, Ouchi N, Ito M, et al.: Adiponectin-mediated modulation of hypertrophic signals in the heart. Nat Med 2004;10:1384-1389.

59. Pfeffer MA, Claggett B, Diaz R, et al.: Lixisenatide in patients with type 2 diabetes and acute coronary syndrome. N Engl J Med 2015;373:2247-2257.

60. Marso SP, Daniels GH, Brown-Frandsen K, et al.: Liraglutide and cardiovascular outcomes in type 2 diabetes. $\mathrm{N}$ Engl J Med 2016;375:1834-1844.

61. Holman RR, Bethel MA, Mentz RJ, et al.: Effects of once weekly exenatide on cardiovascular outcomes in type 2 diabetes. N Engl J Med 2017;377:1228-1239.

62. Bethel MA, Patel RA, Merrill P, et al.: Cardiovascular outcomes with glucagon-like peptide-1 receptor agonists in patients with type 2 diabetes: a meta-analysis. Lancet Diabetes Endocrinol 2018;6:105-113.

63. Lane W, Weinrib S, Rappaport J, Hale C: The effect of addition of liraglutide to high-dose intensive insulin therapy: a randomized prospective trial. Diabetes Obes Metab 2014;16:827-832.

64. Jendle J, Testa MA, Martin S, et al.: Continuous glucose monitoring in patients with type 2 diabetes treated with glucagon-like peptide-1 receptor agonist dulaglutide in combination with prandial insulin lispro: an AWARD-4 substudy. Diabetes Obes Metab 2016;18:999-1005.

65. Bajaj HS, Venn K, Ye C, et al.: Lowest glucose variability and hypoglycemia are observed with the combination of a GLP-1 receptor agonist and basal insulin (VARIATION study). Diabetes Care 2017;40:194-200.

66. King AB, Philis-Tsimikas A, Kilpatrick ES, et al.: A fixed ratio combination of insulin degludec and liraglutide (IDegLira) reduces glycemic fluctuation and brings more patients with type 2 diabetes within blood glucose target ranges. Diabetes Technol Ther 2017;19:255-264.

67. Davies M, Pieber TR, Hartoft-Nielsen ML, et al.: Effect of oral semaglutide compared with placebo and subcutaneous semaglutide on glycemic control in patients with type 2 diabetes: a randomized clinical trial. JAMA 2017;318:1460-1470.

68. Blundell J, Finlayson G, Axelsen M, et al.: Effects of onceweekly semaglutide on appetite, energy intake, control of eating, food preference and body weight in subjects with obesity. Diabetes Obes Metab 2017;19:1242-1251.

69. Mills EP, Brown KPD, Smith JD, et al.: Treating nonalcoholic fatty liver disease in patients with type 2 diabetes mellitus: a review of efficacy and safety. Ther Adv Endocrinol Metab 2018;9:15-28.

Address correspondence to: Helena W. Rodbard, MD Endocrine and Metabolic Consultants 3200 Tower Oaks Blvd., Suite 250 Rockville, MD 20852

E-mail: hrodbard@comcast.net 